The Freshwater Medusa Limnocodium sowerbyi in the Royal Botanic Society's Gardens, Regent's Park.

IT may be of interest to record the reappearance of the freshwater jellyfish, Limnocodium (Craspedacusta) sowerbyi, in the Victoria Regia tank of the Royal Botanic Society's Gardens, Regent's Park. The medusæ were found by us in large numbers on June 30, and some persisted over the week-end. The specimens are mostly fully grown, with an umbrella diameter up to about $13 \mathrm{~mm}$. They resemble in every way the specimens first described by Allman and Lankester. These remarkable freshwater medusæ were first discovered in Regent's Park in 1880, and are reported to have reappeared there for four or five years ; they have apparently not been noticed in the tank in recent years. Since its original discovery in 1880 , the jellyfish has, however, been recorded from tanks in botanical gardens in other towns in England, in France, Germany, and the United States.

The most recent appearance of Limnocodium in England that we can trace, was in the Victoria Regia tank in the Botanical Gardens in Birmingham, where they were collected by Prof. Boulenger in 1912. Apparently the same species was found by Prof. Carman in a creek near Frankfort, Kentucky, in 1916, whilst an allied species, $L$. kawaii, has been recorded from a river in China.

$$
\begin{gathered}
\text { Bedford College, } \\
\text { London, N.W.1, } \\
\text { July } 2 .
\end{gathered}
$$

W. U. FLOWER.

S. LOCKYER.
The Complementary Nature of the Quantum Theory.

ProF. BoHr has kindly informed me that in the last chapter of my recently published book on quantum mechanies, the reference to his work on the complementary nature of the quantum theory (described in the supplement to NATURE of April 14, pp. 579-590) may perhaps give rise to misunderstanding. When I was last in Copenhagen, in September of the past year, Prof. Bohr was away at the congress in Como, and the views which had been recently developed by Heisenberg and himself were elucidated to me at the Institute for the purpose of this last chapter. In the discussions, use was frequently made of a mode of probability calculation similar to that used in earlier work on the statistical formulation of quantum mechanics, but which appeared to me to be more simple and direct. Prof. Bohr points out that the wording of the chapter may create the impression that these calculations were primarily developed in connexion with the new ideas, whereas they may be said to be characteristic of the whole recent development of the quantum theory. When Prof. Bohr was in Cambridge in November, I happened to have neither the manuscript (then in the press) nor the proof of this chapter (then not yet printed), otherwise this impression would doubtless have been noticed and removed.

Pembroke College,

Cambridge, June 20.

$$
\text { G. Birtwistrle. }
$$

\section{A Tetraploid Saxifraga of known Origin.}

THE results of genetical studies, completed up to the $\mathrm{F}_{2}$ generation this year, and of preliminary cytological investigations, enable us to add another to the increasing list of known tetraploids amongst plants. Crossing Saxifraga rosacea with S. granulata, a small $F_{1}$ generation was raised the plants of which were uniform, except that one showed abnormal development of the petals in most of the flowers. The general balance of characters was towards the male parent (S. granulata). One of the $F_{1}$ plants with normal flowers was selfed and a large $F_{2}$ generation (436 individuals) raised. The plants of this generation were remarkably uniform, except that petal abnormalities appeared in a few or majority of flowers in five plants. No trace of segregation towards the distinct habit and flower characters of the two parents could be traced.

Chromosome counts have been made by Mr. R. 0 . Whyte, of Cambridge, who reports that the $F_{2}$ material has 32 chromosomes in the anthers, the number in this generation being double that in its predecessors. The reduction divisions in the $F_{1}$ are most irregular and, at present, difficult to interpret completely. A full account of the work is being prepared for publication. E. M. MarSDEN-Jones. W. B. TURRILL.

Kew, June 20.

The Colour of the Peacock's 'Eye.'

WITH reference to Lord Rayleigh's observations on the colour of the peacock's 'eye' in Nature of May 26 , it may be of interest to note the remarkable change in the colour of the filamentous groundwork of the train effected by wet-a peacock living in the open appears in rainy weather to have this part of the train copper-red instead of green, though the 'eyes' remain of the usual colour. This observation applies only to the ordinary peacock; the black. winged mutant has a coppery train when dry, while the very distinct Burmese peacock and its hybrid with the common bird generally show much pinkishred in the train; both of these, by the way, show a large amount of black in the wing. What the trains of peacocks of these three kinds look like when wet $I$ do not know, having observed them chiefly in the Zoological Gardens, where they are kept in aviaries with shelter always available, and so do not get wet.

Ordinary daylight would also appear in some cases to effect a considerable change in the colour of the train of stuffed peafowl, the specimens in the peacock case at the Natural History Museum being abnormally blue, except the bird shown in display, which is a new one. Yet a peacock in the Horniman Museum, exposed to a far stronger light, has kept its normal coloration for years; but it has not been exposed nearly so long.

F. FINN.

\section{Spectrographic Detection of 'Traces.'}

IN the May issue of the Journal of the Chemical Society Dr. J. A. N. Friend, in a paper entitled "Experiments on Transmutation" (pp. 1321-1324), announces negative results of examinations by spectral means for 'traces' possibly formed in specimens of barium sulphate, silver foil, and gold foil by bombardment from a source of radium $-D,-E$, and $-F$, and also by the action of radium emanation.

He states: "If any kind of transmutation had taken place, its quantity was too minute to admit of detection spectroscopically."

It is desirable to point out that as only spark, and not D.C. arc, spectra were used, this statement is open to question: arc spectra are so much more powerful in revealing 'traces' that they should always be employed if possible for this purpose. Further, if spectral examination is contemplated as the final stage of an investigation, the latter should be so planned that arc spectra can be used.

Batchelor, Robinson and Co., Ltd., J. R. Green. Llanelly.

No. 3063, VoL. 122] 